\title{
A SURVEY ON ECG SIGNAL MONITORING THROUGH SENSOR AND PREDICTION OF HEART ATTACK WITH THE HELP OF OPTIMIZED NEURAL NETWORK USING GENETIC ALGORITHM
}

\author{
Amit S. Wale ${ }^{1}$, Prof. Shilpa S. Sonawani ${ }^{2}$, Prof. Shridevi C. Karande ${ }^{3}$
}

\begin{abstract}
Heart Attacks are the major cause of death in the world today, particularly in India. The need to predict this is a major necessity for improving the countries healthcare sector. Accurate and precise prediction of the heart disease mainly depends on Electrocardiogram (ECG) data. Heart disease is a major life threatening disease that cause to death and it has a serious long term disability. The time taken to recover from heart disease depends on patient's severity. Heart disease diagnosis is complex task which requires much experience and knowledge. Nowadays, health care industry contain huge amount of health care data, which contain hidden information. Advanced data mining techniques along with computer generated information are used for appropriate results. Neural Network is widely used tool for predicting heart attack. A Heart Attack Prediction System we are going to develop using Neural Network and Genetic Algorithm. This system calculates the number of hidden nodes for neural network which train the network with proper selection of neural network architecture and uses the global optimization of genetic algorithm for initialization of neural network.
\end{abstract}

KEYWORDS: ECG (Electrocardiogram), Neural Network, Genetic Algorithm.

\section{INTRODUCTION}

The electrocardiogram (ECG) is the most important bio signal used by cardiologists for diagnostic purposes. The ECG signal provides key information about the electrical activity of the heart. The heart signals are taken from ECG, which is known as Electrocardiography. That the heart signals are picked by using electrodes in arms, leg, chest of our body. By using this signal heart disorder can be find out. Depend on the shape of the ECG waveform, find out the cardiac health. ECG signal readings and their analysis are carried out from signal processing. Today signal processing plays a major role in ECG signal analysis and

\footnotetext{
${ }^{1}$ PG Student, Department of Computer, Maharashtra Institute of Technology, Pune University, Pune, India

${ }^{2}$ Professor, Department of Computer, Maharashtra Institute of Technology, Pune University, Pune, India

${ }^{3}$ Professor, Department of Computer, Maharashtra Institute of Technology, Pune University, Pune, India
} 
interpretation. The aim of ECG signal processing is diverse and comprises the Improvement of measurement accuracy and reproducibility (when compared with manual measurements) and by taking out the information is not readily available from the signal through visual assessment. ECG is composite from 5 waves - P, Q, R, S and T. This signal could be measured by electrodes from human body in typical engagement [2].

Heart Attacks are the major cause of death in the world today, particularly in India. The need to predict this is a major necessity for improving the countries healthcare sector. Accurate and precise prediction of the heart attack mainly depends on Electrocardiogram (ECG) data. Neural Network is widely used tool for predicting heart diseases diagnosis. A Heart Disease Prediction System is developed using Neural Network and Genetic Algorithm. This system calculates the number of hidden nodes for neural network which train the network with proper selection of neural network architecture and uses the global optimization of genetic algorithm for initialization of neural network [1].

In today's world, an optimal and intelligent problem solving approaches are required in every field, regardless of simple or complex problems. Researches and developers are trying to make machines and software's more efficient, intelligent and accurate. This is where the Artificial Intelligence plays its role in developing efficient and optimal solutions. Data mining techniques are used to explore, analyze and extract data using complex algorithms in order to discover unknown patterns in the process of knowledge discovery. Prediction is done with the help of available knowledge or previous values so accuracy in prediction is the main challenge. The artificial neural network (ANN) can use for pattern recognition, classification as well as prediction because it is based on biological neurons, an artificial neural network (ANN) is a self-adaptive trainable process that is able to learn to resolve complex problems based on available knowledge Genetic algorithm is one of most pervasive and advanced developed heuristic search technique in Artificial Intelligence.

\section{A. SCOPE:}

The System can enhance the accuracy of predicting heart attack and heart attack diseases by optimizing neural network using genetic algorithm on ECG signals. It is used in the following areas -

- In Health care Applications

- For Wellness Management

- For Activity Management

\section{B. OBJECTIVES:}

- The major objective of this research is to monitor heart related activity using ECG sensor for prediction of heart attack using optimized neural network using genetic algorithm and enhance the prediction accuracy.

- Increase the efficiency and prediction accuracy.

- Reduce the Patients death caused by heart attack.

\section{LITERATURE SURVE}

This section describes the work that has been done in the area of health monitoring systems. Jubadi et al.[13] has proposed heart rate monitoring alert via SMS. In this an alert system is used to monitor the heart beat rate of a patient. This heart rate measurement is based on the principle of photoplethysmography (PPG) technique. Then this PPG signal was processed 
using PIC16F87 microcontroller to check the heart beat rate per minute. An alert was given to medical experts or family members via SMS. With the help of this system doctors could monitor \& diagnose patient's condition continuously \& could suggest them precautions if any. Saravanan designed remote patient monitoring system using computer communication networks through Bluetooth, WiFi, Internet Android Mobile. ECG, EMG, Pulse, BP, arterial oxygen saturation, blood glucose concentration \& temperature signals were monitored. They had designed android Bluetooth API \& constructed a simple peer-to-peer messaging system to work between two paired Bluetooth. The monitoring section receives data via Bluetooth, Wi-Fi \& Internet. This system was mainly designed to send data to the doctor.

Purnima et al. [14] proposed health monitoring systems based on GSM \&Zigbee technology. In this ECG, temperature \& heart beat signals are continuously transmitted \& monitored through Zigbee. A Zigbee node was connected to every patient monitoring system. The data are transmitted to the doctors PC via Zigbee as well as GSM technology is used to send data to doctor's mobile.

Singh et al. [15] proposed wireless transmission system which is having a wireless sensor platform along with remote monitoring capability. They have designed sensor nodes for temperature $\&$ heart rate. This sensor data are wirelessly transmitted to the controller using $\mathrm{RF}$ transmitter \& receiver module. This data is also wirelessly transmitted to the remote monitoring station.

Venugopal et al. [16] presented a centralized heart rate monitoring system. The data obtained from sensors of various patients are then transmitted over a WBAN and then this data is transmitted to the main location with the help of Wi-Fi.

Kiran Kumar et al. [17] developed health monitoring system using PSOC mixed signal. They developed data acquisition system to remotely monitor patient's parameters like temperature, heart rate, blood oxygen saturation, blood $\mathrm{pH}$ level \& ECG. In this system doctor was able to monitor patient on PC using Zigbee wireless communication technology.

\section{Different machine learning technique in ECG for classification}

\begin{tabular}{|c|c|c|c|c|}
\hline $\begin{array}{l}\text { Sr. } \\
\text { No }\end{array}$ & Paper Name & $\begin{array}{l}\text { Feature } \\
\text { Extraction/Reduc } \\
\text { tion }\end{array}$ & $\begin{array}{l}\text { Classification } \\
\text { Model }\end{array}$ & $\begin{array}{l}\text { Accurac } \\
\mathbf{y}\end{array}$ \\
\hline 1 & SVM(Support Vector Machine) & & & \\
\hline 1 & $\begin{array}{l}\text { Detection of ECG Arrhythmia using } \\
\text { a differential expert system approach } \\
\text { based on principal component } \\
\text { analysis and least square support } \\
\text { vector machine [18]. }\end{array}$ & $\begin{array}{l}\text { Symptoms that } \\
\text { are obtained } \\
\text { from patients } \\
\text { /PCA }\end{array}$ & SVM & 98 \\
\hline 2 & $\begin{array}{l}\text { Support vector machine classifier } \\
\text { algorithm based on a perturbation } \\
\text { method and its application to ECG } \\
\text { beat recognition systems [19]. }\end{array}$ & $\begin{array}{l}\text { DWT(Discrete } \\
\text { Wavelet } \\
\text { Transform) and } \\
\text { DCT(Discrete } \\
\text { Cosine Transform) }\end{array}$ & SVM & $\begin{array}{l}94.3 \text { with } \\
\text { DWT } \\
96.4 \text { with } \\
\text { DCT }\end{array}$ \\
\hline 2 & FUZZY SET THEORY & & & \\
\hline 3 & $\begin{array}{l}\text { AFC-ECG: An Adaptive Fuzzy } \\
\text { ECG Classifier [20]. }\end{array}$ & DWT & Fuzzy logic & 98.1 \\
\hline 4 & $\begin{array}{l}\text { Classification of cardiac } \\
\text { abnormalities using heart rate signal } \\
{[21] .}\end{array}$ & $\begin{array}{l}\text { Certain parameters } \\
\text { that extracted from } \\
\text { the ECG signals }\end{array}$ & Fuzzy logic & $95-100$ \\
\hline
\end{tabular}




\begin{tabular}{|c|c|c|c|c|}
\hline 3 & $\begin{array}{ll}\text { ARTIFICAIL } & \text { NEURAL } \\
\text { NETWORK } & \end{array}$ & & & \\
\hline 5 & $\begin{array}{l}\text { Combining recurrent neural } \\
\text { networks with eigenvector methods } \\
\text { for classification [22]. }\end{array}$ & $\begin{array}{l}\text { Eigenvector } \\
\text { methods }\end{array}$ & $\begin{array}{l}\text { RNN } \\
\text { MLPNN }\end{array}$ & $\begin{array}{l}98.06 \text { for } \\
\text { RNN } \\
90.83 \\
\text { for } \\
\text { MLPNN }\end{array}$ \\
\hline 6 & $\begin{array}{l}\text { ECG beat classifier designed by } \\
\text { combined neural network model } \\
{[23] \text {. }}\end{array}$ & DWT & ANN & 96.94 \\
\hline 7 & 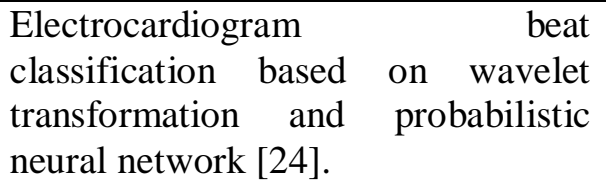 & DWT & PNN & 99.65 \\
\hline 4 & $\begin{array}{l}\text { ROUGH SET THEORY AND } \\
\text { HIDDEN MARKOV MODEL }\end{array}$ & & & \\
\hline 8 & $\begin{array}{l}\text { An Approach to a Rough Set Based } \\
\text { Disease Inference Engine for ECG } \\
\text { Classification [25]. }\end{array}$ & $\begin{array}{l}\text { Important } \\
\text { coefficients: age, } \\
\text { body surface area, } \\
\text { and smoking } \\
\text { history (RST) } \\
\end{array}$ & RST & 87 \\
\hline 9 & $\begin{array}{l}\text { Automatic P-wave analysis of } \\
\text { patients prone to atrial fibrillation } \\
\text { following Cardiac } \\
\text { Surgery using Rough Set Derived } \\
\text { Rules [26]. }\end{array}$ & $\begin{array}{l}\text { Wavelet analysis } \\
\text { Method(HMM) }\end{array}$ & HMM & $\begin{array}{l}65 \% \\
\text { specificit } \\
\text { y } \\
70 \% \\
\text { sensitivit } \\
\text { y }\end{array}$ \\
\hline 5 & HYBRID METHODS & & & \\
\hline 10 & $\begin{array}{l}\text { Fuzzy clustering neural network } \\
\text { architecture for classification of } \\
\text { ECG arrhythmias [27]. }\end{array}$ & $\begin{array}{l}\text { Segments of } \\
\text { arrhythmia }\end{array}$ & MLP-BB+FCNN & $\begin{array}{l}98.9 \text { for } \\
\text { ANN } \\
99.9 \text { for } \\
\text { FCNN }\end{array}$ \\
\hline 11 & $\begin{array}{l}\text { Classification of heart rate data } \\
\text { using artificial neural network and } \\
\text { fuzzy equivalence relation [28]. }\end{array}$ & Spectral entropy & ANN + Fuzzy & $80-85$ \\
\hline
\end{tabular}

\section{SYSTEM OVERVIEW}

From the above literature survey we have concluded that heart activity is very important in health care monitoring system. And it is done through the ECG signals. Different machine learning algorithms were used for predicting the heart diseases as well as heart attack. The all research is done using MATLAB tool.

DISADVANTAGES OF EXISTING SYSTEM:

I. Lack of optimized solution

II. Lack of Prediction accuracy and efficiency.

\section{A. PROPOSED SYSTEM APPROACH}


In the proposed research work to design and implement a system which will predict the heart attack and heart diseases using optimized neural network by genetic algorithm for greater accuracy. System will implement using R tool and java without using MATLAB tool.

\section{ADVANTAGES OF PROPOSED SYSTEM:}

I. Chances of getting optimal solution are more.

II. The proposed system can support Multi-objective.

III. The proposed system can increase the prediction accuracy and efficiency.

\section{B. PROPOSED SYSTEM ARCHITECTURE}

\section{- Sensors:}

These sensors measure attributes of gross user activity, different from narrowly focused vital sign sensors. Good examples are accelerometers used for gait monitoring. Shoe manufacturers like Nike have enabled many of their running shoes with sensors capable of tracking walking or jogging activities. And here ECG sensor capture heart related activities.

\section{- Sensors Data Acquisition:}

This includes operations involved in collecting data from external sensor data sources. Here collect the data from ECG sensor.

\section{- Data Preprocessing:}

This includes operations applied to the data to prepare it for further analysis. Typical preprocessing operations include data cleaning to filter out noisy data elements, data interpolation to cope with missing values, data normalization to cope with heterogeneous sources, temporal alignment, and data formatting.

\section{- $\quad$ Feature Extraction:}

This includes operations for representing the data appropriately and selecting specific features from this representation. This stage is often called feature extraction and selection.

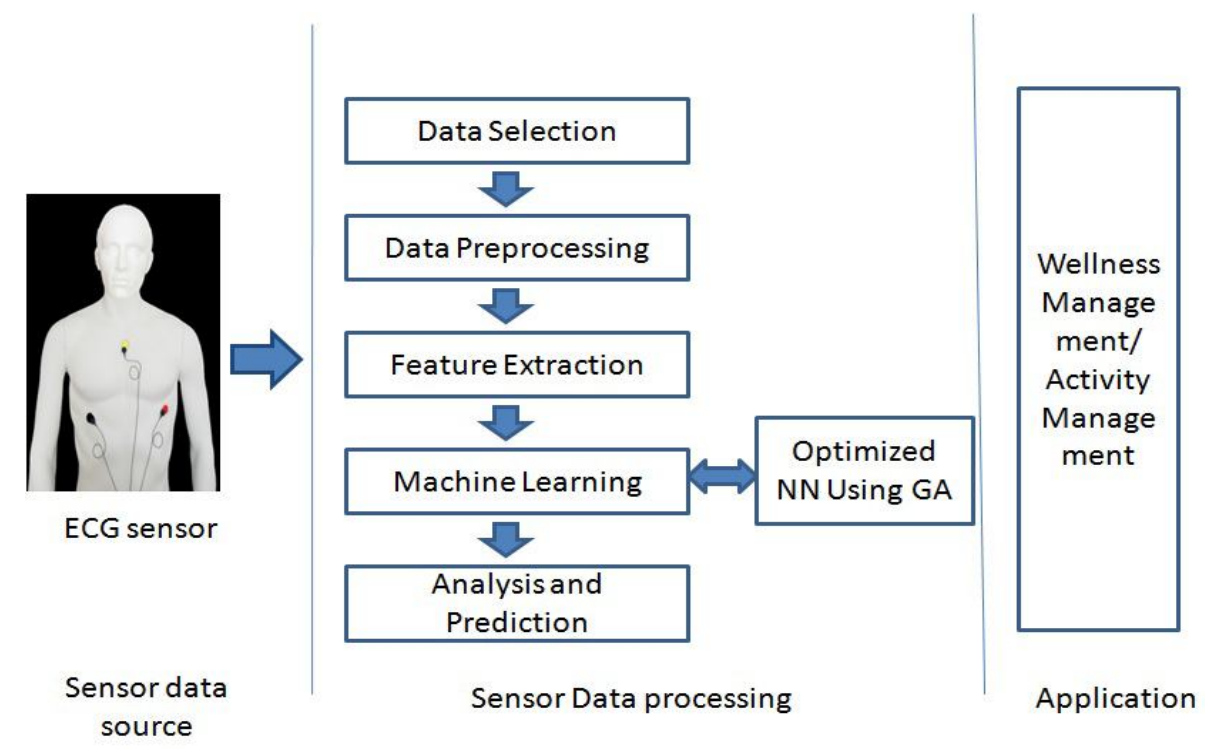

Figure: Proposed System Architecture 


\section{- Machine Learning:}

This stage, also called mining applies knowledge discovery algorithms to identify patterns in the data. Modeling problems can be classified into six broad categories: anomaly detection to identify statistically deviant data, association rules to find dependencies and correlations in the data, clustering models to group data elements according to various notions of similarity, classification models to group data elements into predefined classes, regression models to fit mathematical functions to data and summarization models to summarize or compress data into interesting pieces of information. Here, we are applying Optimized neural network using GA for classification and prediction of heart Attack.

\section{- Analysis and Prediction:}

This stage includes operations for analysis and prediction of the results of the machine learning process.

\section{- Wellness or Activity Management:}

The analysis and prediction is useful for application like wellness management or activity management for the person.

\section{IV.CONCLUSION AND FUTURE WORK}

The ECG is mainly used for diagnosis of heart disease. Genetic Algorithm is used to optimize the initialization of neural network weights. Genetic Neural Network based prediction of heart disease for patient by improving the performance using optimize neural network architecture and predicts whether the patient is suffering from heart disease or not. Also find out possibilities of heart attack based on heart activities. Back propagation is having disadvantage like slow convergence, long training time and local minima. Genetic algorithm is use to solve this problem and gives optimal result as well as get accuracy to predict heart attack.

As the healthcare domain is dynamic and this issue is a challenge to the data mining. It is also a forcing motivation to the data mining applications in healthcare. This dynamism gives way to new horizons and more data mining applications will be employed to discover new patterns and associations. In the view of the subjects examined in this study, future data mining studies seem to take place, not limited but in considerable weight, in distributed data mining applications and text mining algorithms. With the help of data mining algorithms, the classification performance increases. This can be further enhanced and expanded with more prediction algorithm for major life threatening diseases. The further enhancement observes on utilizing different method that provides higher accuracy in feature extraction and classification.

\section{ACKNOWLEDGEMENT}

I would like to take this opportunity to express my thanks to my guide Prof. S. S. Sonawani and co-guide Prof. S. C. karande for their esteemed guidance and encouragement. Their guidance always helps me to succeed in this work. I am also very grateful for their guidance and comments while designing part of my research paper and learnt many things under their leadership.

\section{REFERENCES}


[1] D. K. Ravish, Nayana R Shenoy, Dr.K.J.Shanthi, S.Nisargh, "Heart Function Monitoring, Prediction and Prevention of Heart Attacks: Using Artificial Neural Networks", IEEE-2014 International Conference on Contemporary Computing and Informatics (IC3I).

[2] J. P. Kelwade, S. S. Salankar, "Prediction of Cardiac Arrhythmia using Artificial Neural Network", International Journal of Computer Applications (0975 8887) Volume 115 No. 20, April 2015.

[3] Poonam Sao, Rajendra Hegadi, Sanjeev Karmakarl, "ECG Signal Analysis Using Artificial Neural Network", International Journal of Science and Research (IJSR)- 2013.

[4] Masanao Nakano, Toshihiro Konishi, Shintaro Izumi, Hiroshi Kawaguchi, Masahiko Yoshimoto, Instantaneous "Heart Rate Detection Using Short-Time Autocorrelation for Wearable Healthcare Systems”, 34th Annual International Conference of the IEEE EMBS- 2012.

[5] Dimitra Azariadi, Vasileios Tsoutsouras, Sotirios Xydis, Dimitrios Soudris, "ECG Signal Analysis and Arrhythmia Detection on IoT wearable medical devices", IEEE- 2016 5th International Conference on Modern Circuits and Systems Technologies (MOCAST).

[6] Medina Hadjem, Osman Salem, Farid Nat-Abdesselam, "An ECG Monitoring System For Prediction Of Cardiac Anomalies Using WBAN", IEEE-2014 16th International Conference on e-Health Networking, Applications and Services (Healthcom).

[7] Dayong Gao, Michael Madden, Michael Schukat, Des Chambers, Gerard Lyons, "Arrhythmia Identification from ECG Signals with a Neural Network Classifier Based on a Bayesian Framework", 2009.

[8] Neerajkumar Sathawane, Pravin Kshirsagar, "Prediction and analysis of ECG signal behavior using soft computing", IMPACT: International Journal of Research in Engineering and Technology (IMPACT: IJRET)-2014.

[9] M.A Chikh, N. Belgacem, F. Bereksi Reguig, "The Use of Artificial Neural Network to Detect the Premature Ventricular Contraction (PVC) Beats", 2010.

[10] Tsu-Wang. Shen, Hsiao-Ping Shen,Ching-Heng Lin, "Detection and Prediction of Sudden Cardiac Death (SCD) For Personal Healthcare" , Proceedings of the $29^{\text {th }}$ Annual International Conference of the IEEE EMBS-2007.

[11] Bhuvaneswari Amma N.G., "Cardiovascular Disease Prediction System using Genetic Algorithm and Neural Network", International Conference on Computing, Communication and Applications .IEEE2012.

[12] Nilakshi P. Waghulde, Nilima P. Patil, "Genetic Neural Approach for Heart Disease Prediction", International Journal of Advanced Computer Research Volume-4 Number-3 Issue-16 September-2014.

[13] Warsuzarina Mat Jubadi, Siti Faridatul Aisyah Mohd Sahak, "Heartbeat Monitoring Alert via SMS" 2009 IEEE Symposium on Industrial Electronics and Applications (ISIEA 2009), October 4-6, 2009, Kuala Lumpur, Malaysia.

[14] Purnima, Puneet Singh, "Zigbee and GSM Based Patient Health Monitoring System”, Interntional Conference on Electronics and Communication System (IECS -2014).

[15] Nisha singh, Sr. Asst. Prof. Ravi Mishra, "Microcontroller Based Wireless Temperature and Heart Beat Read-Out", IOSR Journal of Engineering (IOSRJEN), (Jan. 2013), PP 01 -06.

[16] Kala Venugopal, Amit Kumar, "Centralized Heart Rate Monitoring and Automated Message Alert System using WBAN”, International Journalof Scientific and Research Publications, Volume 3, Issue 9, September 20131 ISSN 2250-3153.

[17] D.J.R.Kiran Kumar, Nalini Kotnana, "Design and Implementation of Portable health monitoring system using PSOC mixed signal Array chip",International Journal of Recent Technology and Engineering (IJRTE), ISSN: 2277-3878, Volume-1, Issue-3, august 2012.

[18] K. Polat, S. Gunes; "Detection of ECG Arrhythmia using a differential expert system approach based on principal component analysis and least square support vector machine"; Applied Mathematics and Computation 186 (2007) 898-906.

[19] N. Acir; "A support vector machine classifier algorithm based on a perturbation method and its application to ECG beat recognition systems"; Expert Systems with Applications 31 (2006) 150-158.

[20] W. K. Lei1, B. N. Li1, M. C. Dong, and M. I. Vai; “AFC-ECG: An Adaptive Fuzzy ECG Classifier A”.; (Eds.): Soft Computing in Industrial Applications, ASC 39, (2007), 189-199.

[21] U. R. Acharya, P. S. Bhat, S. S. Iyengar, A. Rao, S. Dua; "Classification of heart rate data using artificial neural network and fuzzy equivalence relation"; Pattern Recognition 36 (2003) 61 - 68.

[22] S. Mitra, M. Mitra, and B.B. Chaudhuri; "An Approach to a Rough Set Based Disease Inference Engine for ECG Classification" ; IEEE Transactions on Instrumentation and Measurement; 55, 6, (2006), 21982206.

[23] L. Clavier I J.-M. Boucher, R. Lepage, J.-J. Blanc, J.-C. Cornily, “ Automatic P-wave analysis of patients prone to atrial fibrillation"; Medical \& Biological Engineering \& Computing 40 (2002), 63-71. 
[24] E. Derya Ubyli; "Combining recurrent neural networks with eigenvector methods for classification of ECG beats"; Digital Signal Processing; 19, 2 (2009), 320-329.

[25] I. Güler and E. Derya beyl I; "ECG beat classifier designed by combined neural network model"; Pattern Recognition, 38, 2,( 2005), 199-208.

[26] S.-N. Yu, Y-H. Chen; "Electrocardiogram beat classification based on wavelet transformation and probabilistic neural network"; Pattern Recognition Letters 28 (2007) 1142-1150.

[27] Y. zbay, R. Ceylan, B. Karlik; "A fuzzy clustering neural network architecture for classification of ECG arrhythmias"; Computers in Biology and Medicine 36 (2006) 376-388.

[28] U. R. Acharya, A. I. Kumar P. S. Bhat, C. M. Lim I S. Slyengar, N. Kannathal I S. M. Krishnan; "Classification of cardiac abnormalities using heart rate signals"; Med. Biol. Eng. Comput., 42 (2004), 288-293. 